\section{Nail Chronology: The Use of Technologically Derived Features}

\section{ABSTRACT}

A technology-based nail chronology is presented. This chronology is derived from a typology based on a combination of general information about the historical developments of the technology applied by the nail manufacturing industry and the periods of actual use for each of twelve basic nail types presently identified as having been used in Louisiana. The author believes that the approach used to establish the Louisiana Nail Chronology can also be used to establish accurate nail chronologies in other regions.

\section{Introduction}

Nails are artifacts commonly found at historic sites. The frequency of their occurrence has encouraged archaeologists to use them as dating tools, supplementing chronologies based on ceramics, glass, and other artifacts. The nail chronologies in common use among archaeologists; however, have not been as reliable as the glass and ceramic chronologies. A reliable chronology is needed to make nails more useful as dating tools. To be reliable the nail chronology should be based on accurately dated nail types, and it should be useful for archaeologists in the field and in the laboratory. To answer this need the Louisiana Nail Chronology has recently been developed. This chronology is based on twelve basic types of nails, sampled from dated buildings. The nail types are readily identifiable and are based on the structure and the physical characteristics of the nails (here called features) that result from dateable technological developments in the history of nail manufacture. Each of the general methods of nail manufacture leaves readily identifiable features on nails. These features are indicative of the technology used in the manufacture of nails, thus because nail manufacturing technology changed over the course of time, the features are temporally significant.
A standard nail chronology used today is one developed by Lee H. Nelson in 1968 (Nelson 1968). This chronology was severely simplified by Ivor Noël Hume (1972). In his chronology Nelson uses the style (referred to here as "form") of the nail, burrs, and head style to date nails. To use his chronology one compares a nail to those illustrated in the pamphlet to find the closest match. An earlier work, by Henry C. Mercer (1924), is based on samples of nails from several houses in Pennsylvania; however, this pioneering work provides some misinformation. For instance, Mercer shows a photograph of a selection of cut nails that are incorrectly identified as "hammer-headed" (Mercer 1924:9). These nails are completely machine-made by a process that will be discussed later. Mercer does illustrate burrs (1924:7), though his conclusions about the dates of the appearance of these are not necessarily applicable beyond the houses he studied. These chronologies were a good start, based on such information as was available at the time. One of the best attempts at establishing a nail chronology is that by Maureen Phillips (1989). She used nails from dated structures to establish the actual time that a nail type was used. Her nail typology is primarily based on manufacturing features, though it is limited to the houses she studied and may not have a general or regional application.

While cataloging a collection of several thousand nails from a house built in the 18th century and continuously occupied since, the author was faced with nails that could not be matched with any of those illustrated or described by either Nelson or Mercer. In addition, numerous nails that appeared to be hand-made had burrs, presumably a feature of cut nails.

Experiences with the problems of existing nail typologies and chronologies lead the author to collaborate with Jay D. Edwards, of Louisiana State University, in the study of nails. The results of that study were published in a general interest monograph devoted to 19th century-nails in Louisiana (Edwards and Wells 1993). The 
following article is based in part on research for that publication and on additional research not included in the book. The chronology presented here differs from that published in our book in one respect: the nail designated as Type 9 is replaced with a different nail. The reason for eliminating it is discussed below. The scope of this article is limited to ferrous house nails. The chronology presented here is based heavily on the historical development of nail manufacture, thus a brief technological history is first presented, followed by a general description of the various types of nails produced by methods employed in each stage of technological development of the nail industry. Finally, the Louisiana Nail Chronology is presented. This section briefly discusses the method used to develop the chronology, which can also be applied in other localities. A short lexicon of some technical terms used here is appended.

\section{A Brief History of Nail Manufacturing Technology}

Beginning in the late 18 th century great changes began in the technology of nail manufacturing. Through the course of the 19th century the American nail industry developed from small, often part-time, cottage-level concerns to large industrial establishments. The technological development of the nail industry closely followed developments in other fields of iron manufacturing technology. Improvements in iron production, synchronized machinery, steam power, iron casting, and eventually steel manufacture were soon followed by changes in nail manufacturing technology. Each stage of nail manufacturing technology has left readily observable, temporally significant evidence on the nails so produced. This evidence is found in the metal used and the characteristic features resulting from the various changes in the production of nails. These pieces of temporally significant evidence may properly be called "features" (from Latin facere "to make") rather than "attributes" ( ad + tribuere "to bestow") because each piece of evidence is characteristic of a stage in the development of nail manufacturing technology rather than a value that is ascribed to aspects of the appearance of a given nail. Identification of the nail types in the Louisiana Nail Chronology is based on these nail features. Historical background is included in a brief review of the evolution of the technology of the nail manufacturing industry.

\section{Metals}

Common house nails were made from one of two types of iron: wrought iron or steel. Determining which of these two forms of iron is used and the salient features of each is the first step in establishing the temporal significance of any nail sample. A brief history of 18th and 19th century iron and steel manufacturing technology is presented to introduce the reader to this subject.

\section{Wrought Iron}

Wrought iron is a ductile two component metal consisting of almost pure metallic iron and moderate amounts of a siliceous slag (Aston and Story 1939:1). There are traces of other elements which are regarded as contaminants. This form of iron is "wrought," meaning worked rather than cast in its final shape by pouring liquid iron into molds. In the 18th century one of two methods was generally employed to reduce iron ore into metallic iron. These are referred to as the direct method and the indirect method. Which of these two methods was used cannot be discerned in the final product. The entire process, from mining to extraction and refinement, may be found in Georgius Agricola's De Re Metallica (Agricola 1950), originally published in 1556.

The roughly consolidated blooms, sometimes called "muck bars," were further refined in the chaffery into "merchant bars" that were next drawn into commonly used stock sizes of bars 


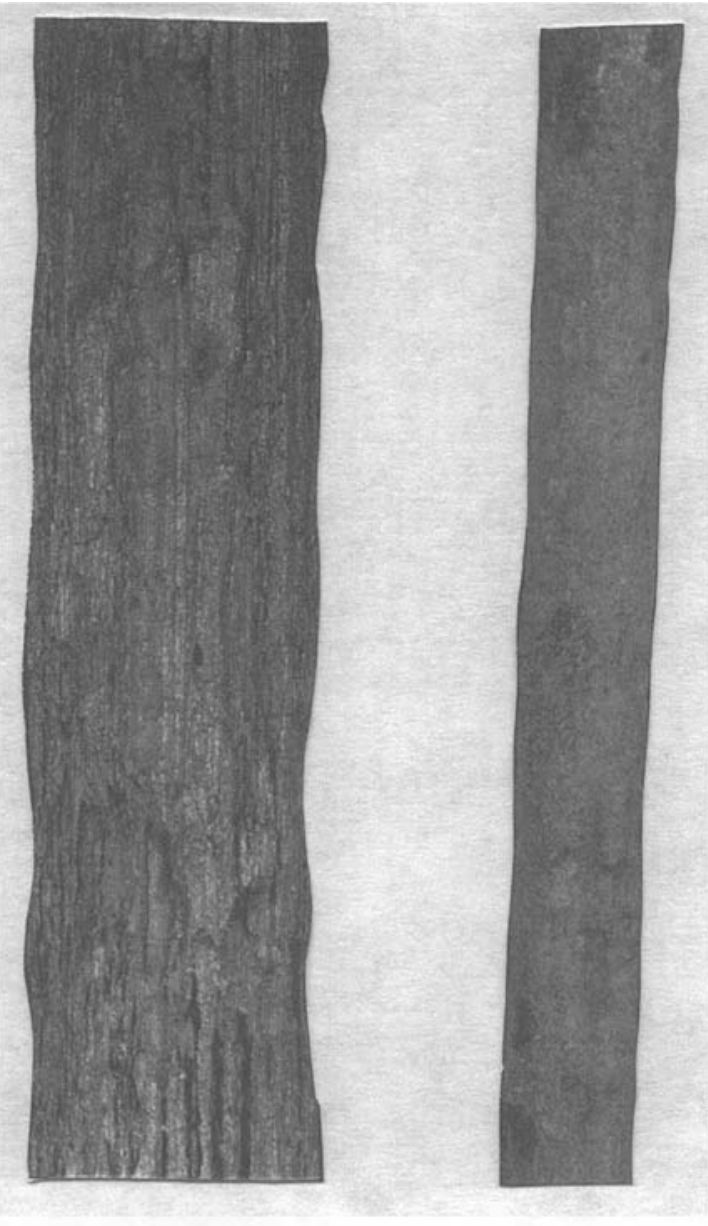

FIGURE 1. Surfaces of iron (left) and steel (right) (Edwards and Wells 1993).

and plates. Some bars were next sent to the rolling and slitting mill to be made into nail plates and then nail rods.

During the 15 th century an additional refining step was added. It involved the reheating of the iron to a welding heat and again hammering it to consolidate the iron better by working out as much of the slag and impurities as possible. Another step in the refining of iron was added in the late 18 th century. It consisted of folding the bars over and stacking several of these, one on the other, then welding them all together to produce a higher quality, cleaner iron (Mott 1983:28, 35-36).

The last step in whatever process was used was to draw out the iron into stock sizes of bars, flat stock, and rods. Until the 1780s the drawing out process was accomplished by forging the bars using a water powered helve hammer and hand labor, with swedges used to size and shape the stock. In 1784 an English patent was issued for turning out stock using grooved rollers (Mott 1983:37-39). The grooved rollers both consolidated and shaped the hot iron.

When cleaned to bare metal wrought iron can be readily identified by its wood-like grain (Figure 1). The wood-like grain is caused by the silicious slag that could not be removed from the bloom; it was drawn out with the iron, becoming longitudinal glassy veins in the bar. The metallic part of wrought iron is chemically almost pure iron. Typically, a wrought iron bar may have $1 \%$ to $3 \%$ mixed slag and traces of other impurities (Aston and Story 1939:2, 20-26). Batches of wrought iron may vary considerably in both chemical constituents and their proportions. Even iron samples from the same ores and the same bloomery may differ significantly from bar to bar, depending on the proportions of flux mixed with the ore, the temperature at which the iron was worked, how long it was held at high temperature, and the worker's diligence in the refining processes.

\section{Steel}

Steel is an alloy of iron and carbon. A low carbon steel, called mild steel, is usually used for nail manufacture. Steel has a crystalline structure, contains insignificant amounts of slag, and does not have the wood-like grain that is characteristic of wrought iron. Steel may be recognized by its fine uniform surface. When rusty steel is cleaned to bare metal, a surface covered with small circular pits is revealed, in contrast 
with wrought iron's longitudinal striations (Figure 1).

Though small quantities of steel have been made for millennia, large scale mass production of steel began in the late 1870 s with the adoption of a modified Bessemer process. Until the perfection of the industrial processes steel had been made by carburizing high grade wrought iron. In the late 1880 s and 1890 s the various Bessemer and open hearth methods of steel making were being developed and perfected. Both Bessemer and open hearth processes involved melting pig iron and blowing oxygen through it, generating an extremely high heat that burns out nearly all of the impurities. Carbon content of the steel was controlled by adding it to the molten steel. The molten metal was next poured into ingot molds (Campbell 1940:5-14). The ingots were then sent to rollers to be formed into rods, sheets, or other shapes. By the middle 1890s steel production, being less labor intensive than wrought iron production, began to replace it in most applications, including nail manufacture.

\section{The Manufacture of Nails}

Each of the methods of nail manufacture leave readily identifiable features on the nails produced.

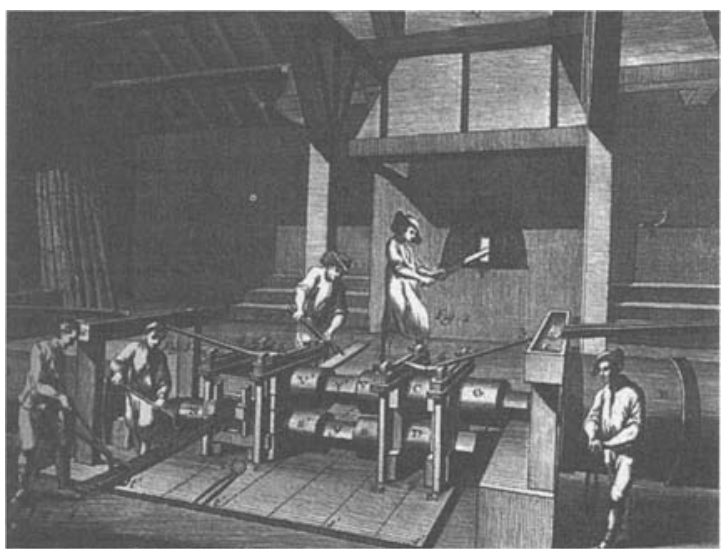

FIGURE 2. An eighteenth century rolling and slitting mill (Diderot 1765).

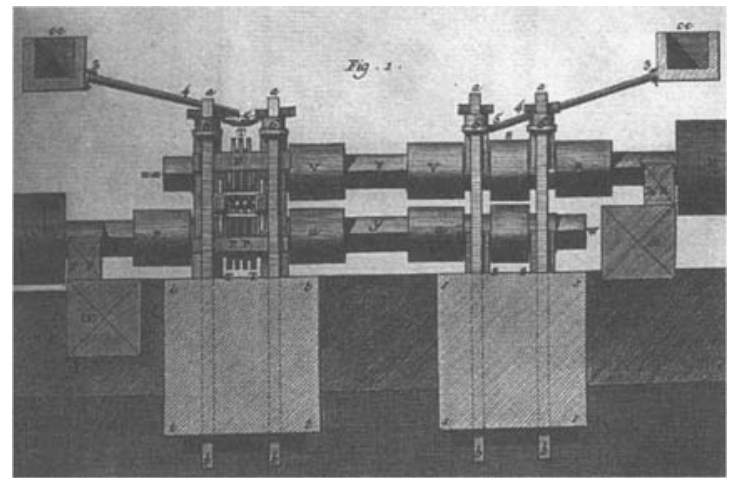

FIGURE 3. Detail of a rolling and slitting machine (Diderot 1765)

These features are indicative of the technology used in the manufacture of nails and because the manufacturing technology changed over the course of time, these features are temporally significant. There are two important divisions of nail manufacturing technology: hand forged and machine made. The earliest of these two, hand forged, will be presented first.

\section{Hand Forged Nails}

Hand forged nails were made from iron nail rods. The older way of making nail rods was by drawing out large bars to a smaller size. This was accomplished by the smith, using a hand hammer or with a helve-hammer. This is a rather slow, labor-intensive process, but it continued to be used even after later technological developments had made it obsolete. Its advantage was that no specialized equipment other than basic blacksmith tools was required. Nails made from forged nail rods are generally square in cross section and have evidence of hammering on all sides and the head.

After their development in the 17th century, rolling and slitting mills made most nail rods (Figure 2). In the mills, bars were heated and run through water powered rollers until they had rectangular cross sections and were about one quarter to one half inch thick, according to the size nail rod that was to be produced. These 
were called nail bars. Each nail bar varied from 6 to $8 \mathrm{in}$. wide and roughly $12 \mathrm{ft}$. long. The rectangular nail bar was then sent through the slitter (Kauffman 1966:34-35). This machine consisted of intermeshing hardened disks that cut the nail plate lengthwise into nail rods (Figure 3).

Nail rods made in slitting mills often do not have perfectly square sides; they are often rectangular, rhomboid, or trapezoid in cross section. The rectangular section is the result of feeding a thin plate through the cutters. Rhomboid and trapezoid cross sections are caused by the pulling action of dull cutter disks. As the nailer, the smith who makes nails, draws out the point of a trapezoidal cross section of nail rod, a valley is sometimes formed in the wider face in the upper part of the shaft. A rhomboid cross section will not have marked effect. The cross section of the original nail rod may extend from under the head down the shaft for a quarter of the length of the nail.

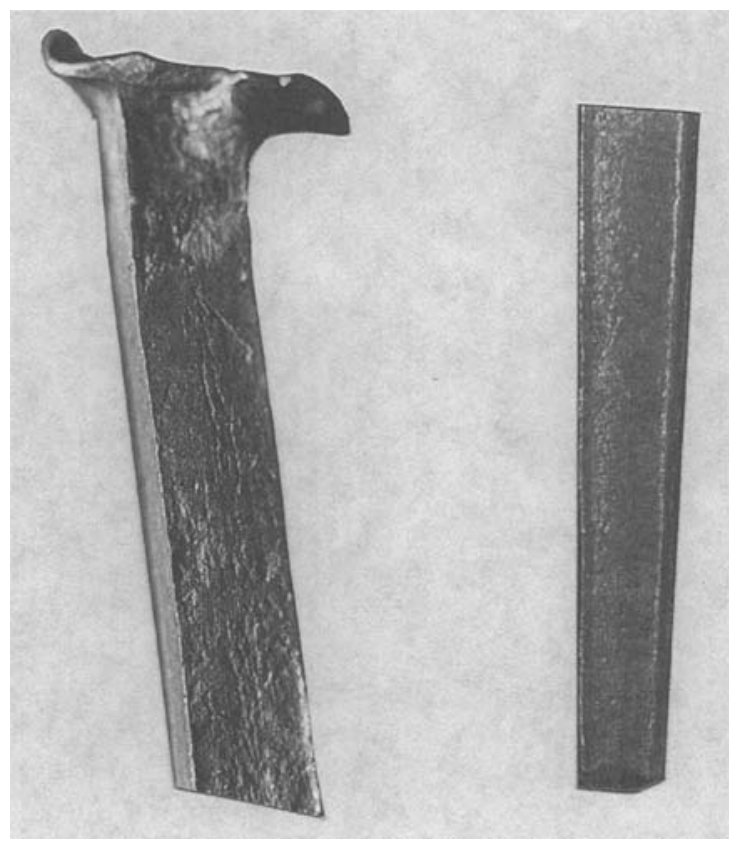

FIGURE 4. Burrs on a forged nail (left) and a cut nail (right).
Hand forged nails may have burrs on the trailing edge of the rod on the same face (Figure 4). The burrs are caused by the cutters dragging a small amount of iron into the slight gap between the cutter disks. The burrs will often be visible on the unmodified part of the shaft below the head and above the tapered part that was drawn to form the point.

Nails were forged using specialized versions of standard blacksmithing tools, including hammer, anvil, and header. The header is a tool that is pierced by a tapered hole that is slightly smaller than the nail rod employed. A standard method used by smiths to forge a nail began with heating the end of a nail rod in the fire. The end was then pointed and the shaft was drawn to a diameter that would slip into the header, a shoulder being left to catch in the header where the head was to be formed. While the rod was still showing color it was nicked above the shoulder and twisted off in the header, leaving the shaft in the hole and a little of the rod projecting above the header. Finally, this projecting piece was "upset," mushrooming it to form the head, completing the nail.

A common feature on nails made from slit stock is a slight depression under the head on one face. This feature suggests an alternative method of heading the nail. Instead of leaving a shoulder to catch in the header, the smith struck the rod on its face, bulging the sides at the place the shaft was to catch the header. The nailer might do this when the nail rod size was the same size or slightly smaller than the hole in the header. On nails made in this way the original unmodified nail rod can be seen between the head and the point taper.

All hand-made nails exhibit hammering on the head and all four sides in the point taper. It is not always possible to tell if a nail is made from forged rods or slit rods, if the nail was drawn from a large slit rod down to a smaller size. This is because the distinct features of the slit rod will be obliterated by the smith's hammering. Shafts often do not taper uniformly from head to point; however, there may be valleys, cold shuts, 
or other evidence that suggests the use of slit rods. A cold shut is an unconsolidated fold of metal hammered against the shaft. Nails may have burrs or vertical drag marks immediately under the head, the result of seating the nail in a tight header. The heads exhibit hammer marks and are somewhat irregular. There are numerous styles of head which may represent functional types. Head styles and functional types, however, are beyond the scope of this study.

Forged nail technology antedates the colonization of America, and limited numbers of forged nails were still being made well into the 19th century. The use of forged nails became progressively less common as cut nail technology improved. Nails and nail rods were imported into the European colonies from the time of their establishment in the New World and were manufactured in limited numbers in the United States into the 19th century, making forged nails not especially useful for dating. Their presence at a site can only suggest the early 19th century or earlier.

\section{Machine-Made Nails}

\section{IRON CUT NAILS}

All cut nails are made from strips of iron or steel called nail plates. The length of the nail is determined by the width of the nail plate, and the thickness of the nail is the same as the thickness of the nail plate. The surface of the nail plate is the surface of the nail's face. The body of the nail, the nail blank, is sheared off the end of the nail plate at an angle so the nail blank describes an acute, usually truncated, triangle. The small end is the point and the large end will be upset to form the head. In cutting the blank from the nail plate the shearing action leaves two features on the nail that are of interest here: the cut face and the burr (Figure 5). All cut nails taper on two sides, the cut faces, and have a uniform thickness on the opposite faces below the pinched area. Though cut nails rarely have

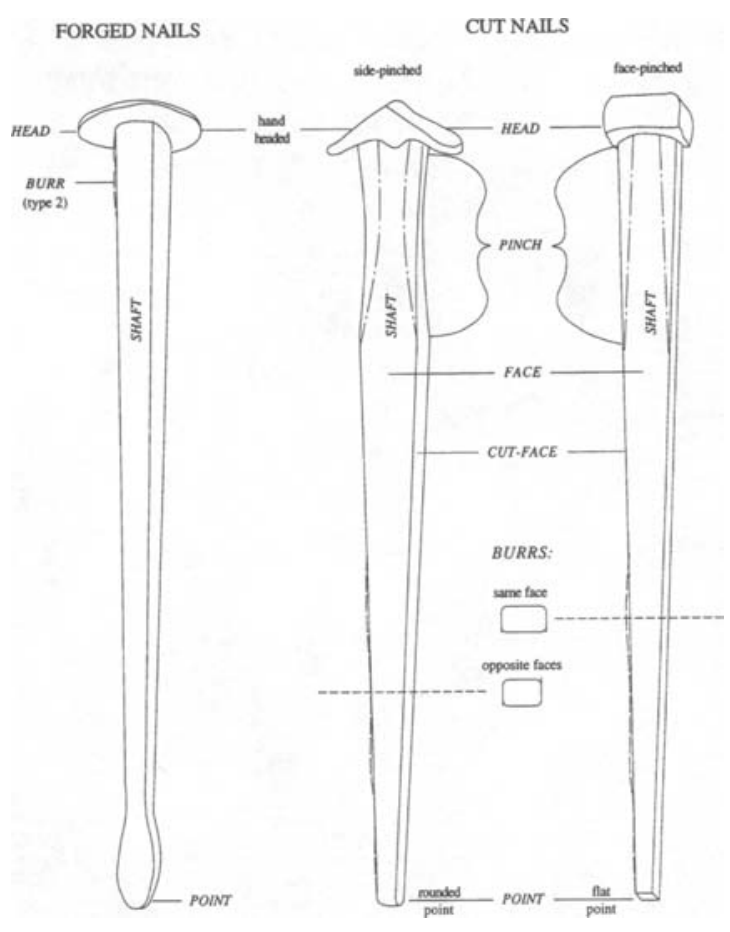

FIGURE 5. Nail nomenclature.

sharp points, some are to be found, usually on early cut nails.

Beginning in the late 18th century, early cut nail manufacture was accomplished in two steps, beginning with the shearing of the nail blank. Then the blank was held in a clamp and headed by hand. The earliest nail cutting machines, like Nathaniel Reed's (Loveday 1983:13, 18), were manually powered and the nail plate was fed into the shear by hand. After the nail blank was cut off it was put in a vice-like header, leaving a short section of the shaft projecting above the header. This device grasped and crushed the cut faces, resulting in a side-pinched nail. The nailer then struck the projecting part of the shaft with a hand hammer to form the head.

The first successful combined cutting and heading machines were developed and used in the northeastern United States in the early 19th cen- 
tury. The factories used water power to drive the machinery rather than human power, thereby increasing the speed of production and uniformity of the product. Some early, fully machine-made, nails can be hard to distinguish from handheaded cut nails. Both are generally strongly side-pinched, the burr is on opposite faces, both have points that are rounded from front face to back face, and are cross-grained. The heads of machine-headed nails, however, tend to be more

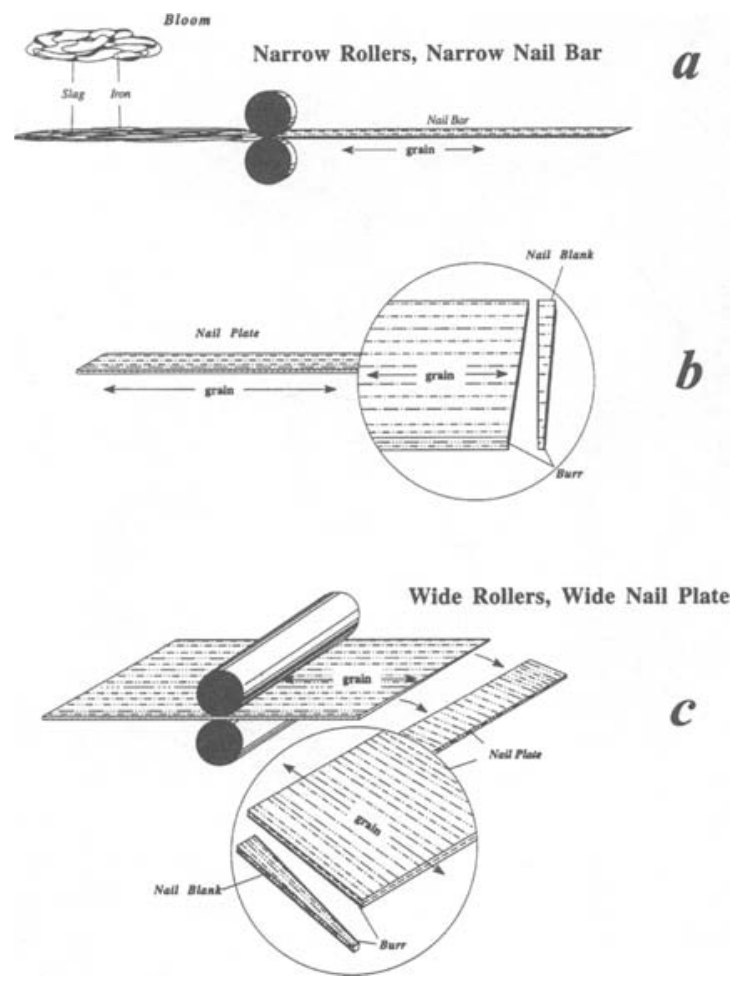

FIGURE 6. Wrought iron grain and methods of making nail plates: a, slag in the bloom is drawn out with the iron, narrow rollers form the narrow nail plate with the grain running the length of the bar, nails cut from narrow nail plates are crossgrained; $b$, narrow rollers form the narrow nail plate with the grain running the length of the bar, nails cut from narrow nail plates are cross-grained; $c$, wide rollers produce sheets, which are then sheared across the grain to produce nail plates, nails made from such plates are in-line-grained (after Edwards and Wells 1993).

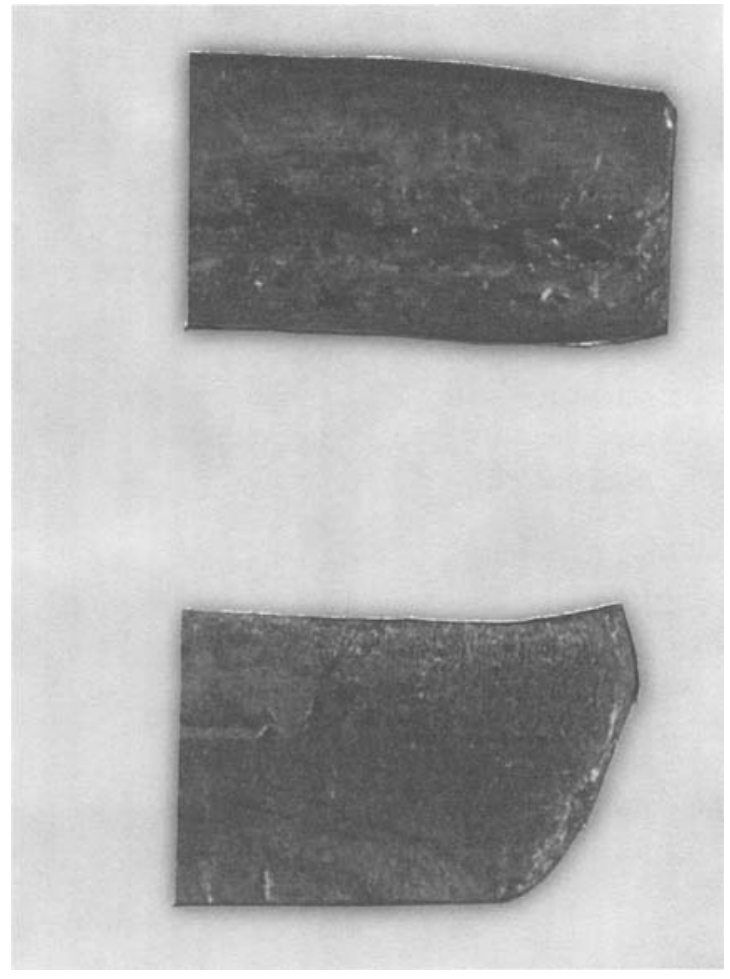

FIGURE 7. Points of cut nails compared. The top point is that of a nail that was cut from a nail plate which was sheared from a sheet. The bottom point is from a nail cut from a narrow nail plate (Edwards and Wells 1993).

regular and thicker than hand-headed nails, and the shafts tend to be uniform in pinch, shearing angle, and general appearance.

Both hand-headed and machine-headed early cut nails were cross-grained. They were cut from narrow nail plates which were produced by rolling mills using narrow rollers (Figure 6). The grain of the iron in these plates runs the length of the plate so the grain of the nail blank, cut from the end of the nail plate, ran across the nail. The rounded edge of the nail plate usually survives at the point. Nails cut from such plates will have points that are rounded from the front face to the back face (Figure 7).

In the hand-fed nail machines the nail plate had to be repositioned for each cut to produce 
the necessary angle for the nail blank. The inevitable, though slight, variation in feed angle resulted in nails that are of variable breadth. With the perfection of the automatic feeder came greater uniformity in shaft breadth and taper. Most of the early cut nail types have burrs on opposite faces, evidence that the nail plates were inaccurately repositioned after each cut.

A major drawback of all cross-grained nails is their tendency to break when clinched, bent, or extracted from the wood. This is because wrought iron is laterally weakened by the slag running across the shaft. Cross-grained cut nails break cleanly along the slag inclusions in the grain. The superior performance of grain-in-line nails, such as hand forged nails, was well understood by Jacob Perkins who advertised, in 1795, a machine that he claimed could produce such nails (Phillips 1989:91). That Perkins' nail machines did not dominate the nail market may be ascribed either to the unreliability of the machines or to the expense of making wide plates before the technology had matured. Grain-in-line cut nails dating from before 1834 have not been found in Louisiana, though they may have been used in Boston before the turn of the century (Phillips 1989).

Large scale manufacture of grain-in-line cut nails awaited the full development of other technologies, especially the art of iron casting and steam power. The narrow rollers of the old water-powered rolling mills were unable to produce wide plates and sheet iron. Though wide rollers had been used since the 18th century they were flexible because of their small diameter, limiting their use to the softer non-ferrous metals (Daumas 1964:252). The demand for wide sheet iron for steam engine boilers was met at first by hammering thick narrow plates under a water powered helve hammer until they were sufficiently wide. By 1803 in England, iron casting technology improved enough that large diameter, rigid, wide rollers could be made of cast iron. It was also there that steam power was first applied to drive machinery (Dickinson 1939). After those developments, wide rollers powered by reliable steam engines could economically produce wide plate and sheet iron. These technologies were soon brought to America (Binning 1938:88).

Steam engines provided reliable power, permitting factories to be established away from the falls of the eastern seaboard rivers to the western coal and iron producing areas. There were three advantages realized from the use of steam power. First, factory layout could be directed for manufacturing efficiency rather than being limited by access to the river and the axle that transferred power from the water wheel. Second, power to the machines was no longer limited by the river's flow rate, rate of fall, and seasonal availability of water. And finally, beginning in the early decades of the 19th century, factories could be located in the west where the greatest demand was. In the west, boats communicated with every town in the Mississippi valley, quickly transporting nails for the ever expanding market.

In 1810 a plant in Pennsylvania had water driven rollers 3-4 ft. long and 16-18 in. in diameter; the following year steam power was first used in a Pittsburgh rolling mill (MackintoshHemphill Company 1953:31-32). In 1832 one of the first cut nail factories was established in Wheeling, (West) Virginia, a town that was soon to be the center of the cut nail industry. In this factory, sheets were rolled and cut into nail plates (Heitmann 1989:311). It appears that by 1830 wide roller technology had come into common use by American nail makers to make an improved, in-line-grained nail.

By the second decade of the 19th century some manufacturers were producing nail plates that were cut from sheets or wide plates (Ure 1865:255; Martineau 1866:613). With this new method, wide rolled plates were cut across the grain-producing nail plates that had the grain running across them. Nails cut from the end of cross-grained nail plates had the grain running from point to head. These nails could be successfully clinched without breaking. All nails that were made by this method have flat points with four sharp corners (Figure 7). 
In the more technologically advanced machines the angle of the nail blank was established without the necessity of repositioning the plate after each cut. A reciprocating cutter, having two cutting edges, each set at the correct angle, came into use at about the same period as the transition from cross-grained to grain-in-line nails. These machines produced nails having the burrs on the same face. This single feature, however, should not be used by itself for establishing the nail date; there are cross-grained nails that have burrs on the same face.

After the nail blank is cut it is mechanically grasped for heading. Grasping by the header clamp deforms the upper end of the shaft just below where the head will be formed. This is another feature of cut nails referred to as the "pinch" (Edwards and Wells 1993). Most of the later nails are face-pinched, though side-pinched nails have been continuously produced from the beginning of cut nail mass production to the present. The most common in-line-grain nail is face-pinched so the edges of the faces are nearly straight from head to point. The heads are usually small, either square or rectangular when viewed from the top and rather blocky. Two functional types of cut nails do not have a pinch: sprigs, which are left unheaded, and brads, whose heads are cut simultaneously with the shaft.

Heading was done cold or at a low heat, putting great stress on the iron, often resulting in small cracks that run with the grain on the face side of the head. The cracks result from the iron separating along the grain under the force of heading. It is common to find long cracks on the cut faces of all iron cut nails, indicating that the iron was poorly consolidated. As iron producers adopted better iron making techniques, the quality of wrought iron improved so that such cracks are less often seen in nails made after the 1840 s.

\section{IRON WIRE NAILS}

Wire was made by pulling a rod through successively smaller holes in a draw plate until the desired diameter was reached. At the end of each drawing the leading end of the wire had to be reduced to the next smaller size and started through the hole so it could be grasped by the clamp that pulled the wire (Ferguson 1965:9094). In iron wire the grain runs the length of the shaft, allowing it to be bent without breaking.

Wire making technology changed little from medieval times until the middle of the 19th century, though water and then steam took the place of human power to pull the wire. Steam was not employed in American wire making until the 19th century (Binning 1938:88-89). Although wrought iron wire had been made for a long time it was not considered suitable for nail making for two main reasons: wrought iron wire could not be made as cheaply as nail plates, and because of their narrow, un-tapered sides, and the softness of iron, wire nails could not be driven into hardwoods without pilot holes. Even so, small iron wire nails called "French points" were made in this country beginning in 1875 with imported French machines. In 1880, the first American wire nail manufacturer began commercial scale operation in Kentucky (The Iron Age 1898).

The manufacture of wire nails begins with feeding the end of a roll of wire into clamps which grasp the length of the shaft with a short length projecting past the clamp. The wire is held in place by teeth in the clamp that make a series of lateral scores found on the upper shaft immediately below the head. The wire projecting from the clamp is mechanically upset to form the head. While still in the clamp, cutter dies squeeze the point on to the shaft, while separating it from the wire roll, then the clamp opens and drops the finished nail; the process begins again as more wire is fed into the machine (Clark 1978:192-193). The same basic design of machine is used in steel wire nail manufacture.

Distinguishing wrought iron wire from steel wire can be difficult. Iron wire for iron wire nails was highly refined and the grain is noticeable only after it has been acid-etched. Recognizing steel wire nails can also be difficult. As steel is drawn through the reducing dies the crystalline structure becomes stretched. This, com- 
bined with the minute longitudinal abrasion of the die, often gives the steel a striated appearance similar to that of iron. It is also possible to tell the difference between iron and steel using powerful microscopes, microphotographs, spectral analysis, and other metallurgical techniques.

\section{STEEL CUT NAILS}

After the steel making processes were perfected and the price for steel was less than that of wrought iron, cut nail manufacturers began to use steel for nails. From the late 1880 s through the 1890 s steel gradually replaced wrought iron in the manufacture of cut nails (Heitmann 1989:30). From 1884 through 1886 only 5\% of cut nails were made of steel. By 1891 three quarters of all cut nails were made of steel. Before the end of the century all cut nails were made of steel. Steel cut nails are still made in small quantities, some on old machines. The manufacturing process is the same for steel and iron cut nails and because there are styles of steel cut nails that resemble early 19th century-nails, it is necessary to determine whether the nail is made from iron or steel.

\section{STEEL WIRE NAILS}

The processes for the manufacture of steel wire nails is essentially the same as that for iron wire nails, though more abrasion resistant materials are now available for use in the dies (Committee of Rod and Drawn Wire Producers 1969:7-9). Though manufacturers began to produce steel wire in the $1860 \mathrm{~s}$, the wire was used mostly for telegraphs, seat springs, and crinolines. Steel wire nails do not seem to have been available until the late 1870s (Loveday 1983:136), possibly because of the expense of steel manufacturing of the day. Steel wire nails were not produced in competitive quantities until the late $1880 \mathrm{~s}$ and early 1890s (Loveday 1983:137). By the turn of the century most nails that were sold were wire nails. By 1920, wire nails had taken over the nail market, leaving cut nails with only $8 \%$ of the market.

\section{The Louisiana Nail Chronology}

The Louisiana Nail Chronology represents an attempt at establishing a system for dating sites and standing structures using nails as dating tools. One of the problems with existing nail chronologies is that they are form-based: their use requires one to compare a sample nail with illustrations of nails to find one that looks similar. The assumption is that similar form indicates similar dates of manufacture and use. This method can be misleading because nails with the same form have been made for over a century. This problem is slightly ameliorated by the brief descriptions of burr location and grain direction.

Mention should be made here of other systems of categorizing nails. The least useful of these, for dating purposes, is by functional type. Functional types are based on the intended or customary use of a particular kind of nail. Functional types are of little use for establishing dates. Additionally, the actual use of any particular nail cannot be known out of its original context. Functional types may be of limited use in describing some nails, in the same manner and with the same skepticism as "arrow head" or "adz" are used to describe prehistoric stone artifacts.

Closely related to functional types is classification by means of head and point style, which meets with the same objection: style has not proved useful for establishing a chronology, though it may be useful in establishing a nail typology. The English used such classifications as "clout" and "rose head" to describe nails and sometimes this may indicate their use; however, not all such terms need to be discarded. There are useful English terms that have specific and limited use, such as "brad" and "sprig." Such terms may be used to describe the form of specific nail classes. For instance, a sprig is a nail made without an apparent head. Care must be taken because one cannot always be certain that a pointed shaft is a sprig. In the case of "brad," both forged and cut brads have a "7" shape, but modern wire brads have a small round head that slightly overhangs the shaft around its diameter. Although functional types and head and point 
styles are not reliable temporal indicators, functional types can be valuable for other purposes. Even after having visited and sampled nails from many late 18th and early 19th century-buildings the author can only make very broad generalizations about how any particular functional type was actually used in that period.

The use of "penny" is avoided because of its vagueness. "Penny" can mean the number of nails that could be bought for a penny, the price per pound of a size of nail, or the price, in pence, for a hundred nails. Today the term has been standardized to describe a size of nail. An additional objection is that "penny" is culturespecific; it is an English system not shared by the French or Spanish in Louisiana. For instance, among the supplies requested from France for the colony in 1759 are "twenty quintals of double caravel nails; thirty quintals of half caravel nails; thirty quintals of caravel nails; forty quintals of shingling nails, a little longer than half-deck nails." The list goes on to describe a total of seven varieties of nail by using named types. The list, however, also includes "twenty quintals of 6-, 7- and 8-inch nails" (Rowland and Sanders 1984:57), a description of nails by length. Interestingly, none of the names of the above types is used by Diderot (1765) to describe nails.

Using patented designs of machines or patent dates for nail machines have been found to be of no use in dating. It is doubtful that it will ever be possible to tell that a particular nail was made by a given machine based on its patent, or even if the machine were built and actually put into service. Many patents were taken out on plausible ideas, often in hopes of making money from litigation against successful manufacturers who could be sued for patent infringement.

Another danger results from using references on the British nail industry for generalizing about nail manufacture in the United States. It should be remembered that throughout the 18th and 19th centuries, the manpower and economic forces of the two countries differed greatly. In Great Britain, and in Europe generally, there was a surplus of manpower. In the U. S. there was a chronic shortage of labor. In England there was considerable resistance, on the part of skilled labor, to the adoption of machinery that could threaten their employment. This resistance retarded the technological development of certain other industries in England, for instance, boots, clothing, and locks. Labor resistance to "labor-saving" machinery has been cited as the chief reason that England continued to produce nails by hand into the late 19th century (Habakkuk 1962:172). In the late 19th century an English nailer could make, by traditional hand forging, about 112 pounds of larger size nails in a day. In a week he earned about 16 shillings (\$3.87). At the same time, an American nailer, operating three machines, could produce $54 \mathrm{kegs}$ of $10 \mathrm{~d}$ nails, and earn $\$ 5.00$ a day (Schoenhof 1974:226-227).

Historical research may indicate that a particular nail was being manufactured, but how does one tell if it was used in a particular region? Taking Lee Nelson's suggestion that local chronologies be developed, the author and Jay Edwards did just that; however, the nail typology on which the Louisiana Nail Chronology is based depends on the identification of significant features. These features include the physical structure or characteristics of the nails that result from dateable manufacturing technology. Each stage in the history of technological development may be discerned on the nail. The use of iron or steel, grain direction, and so on result from stages in the development of nail manufacture technology and thus, indicate a general date for the manufacture of the nail. This method; however, assumes that earlier technologies were discarded as more efficient technologies were developed.

The nail typology derived from technologybased dates is of general applicability only. Such dates do not allow for the use of nails made from obsolete technologies, differences in trade routes, or old nails used in new structures. In order to obtain dates of actual use specific to Louisiana, another method was used to develop a regional chronology. This method follows that of Mercer (1924) and Maureen Phillips (1989) by using dated standing structures as sources of 
dateable nails. Technological features were used to establish nail types; however, dates-of-use were determined by sampling dated historic buildings. Nails selected for this study were functional parts of the structure, pulled from original, permanent parts of the building such as the roof truss, knee walls, jack rafters, sills, purlins, and rafters. Roofs may be replaced several times over the lifetime of a building, thus they were not (with one exception) used as sources for nails. Nails from later additions or repairs, unless they were well dated, were not sampled. Thus, structural nails drawn from the original parts of an 1840 house could be assumed to date from 1840 or earlier.

As the historical background research and nail study began to take shape, houses were selected for dates that coincided with documented changes in nail manufacturing technology. This was done to obtain nail samples that would sharpen the transition period from one nail type to another. Of particular interest was the transition from hand-headed cut nails to fully machine-made nails that started near the beginning of the 19th century. Also of special interest was the period of transition from cross-grained nails to grain-inline nails that took place in the first two decades of the 19th century. Documenting the periods of transition from the use of iron to steel and of cut nails to wire nails was considered less vital because by the late 19 th century-interstate transportation made the shipment from factory to carpenter a matter of weeks, if not days. The transition period can be reliably documented by historical research; however, several buildings from the end of the 19th century were sampled to verify the historical evidence.

The resulting data base used to develop the chronology is summarized in Table 1 . The name of the building is followed by the date of the building's construction. The date is followed by a letter scale from " $\mathrm{A}$ " to " $\mathrm{D}$ " designating confidence in the accuracy of that date. An " $A$ " indicates a firm documentary record from the time of construction; " $B$ " is a building dated to within two years by a combination of documentation and other methods; " $C$ " indicates that the building is dated to within five years by a combination of methods; the scale ends with " $D$ " indicating a building whose construction can be dated to within a decade by a combination of methods. Nails from buildings that could not be dated to within a decade were not used to establish the chronology. Obviously, the " $A$ " buildings are to be preferred as sources for nail samples; however, " $A$ " buildings dating from the years of interest were not always available.

Nail dates based on their use in buildings should be understood to be probabilities; there are abundant opportunities for sample error, especially for the early cut nail dates. Few of the structures built in the 18th century and early 19th century are still standing. Nails from archaeological sites were beyond the scope of the survey. The eventual inclusion of archaeological sites as a source for nail samples may improve the accuracy of the chronology.

\section{How to Determine the Age of a Nail}

As many nails as possible (or as many as the owner will allow!) should be sampled to establish the uniformity of the sample and the types used. In addition, nails should be drawn from as many parts of the original structure as possible, again to establish the uniformity of the sample and, eventually, to develop a functional type system based on nail use.

\section{Diagnostic Features}

Nails should be cleaned of all oxides to expose the bare metal and in order to reveal the diagnostic features. The important features are: material (iron or steel); general uniformity (or lack of it) of the head and shaft; shaft shape, cross section, and taper; the pinch, if present; shape of the point; burr, if present; cold shuts or cracks; and heading method. No one of these features should be relied on for determining the age of a nail. Except for the use of iron or steel none of these features is, in its self, chronologically significant. When the nail features are used together, one may determine the nail type and its time of use. 
TABLE 1

DATA BASE

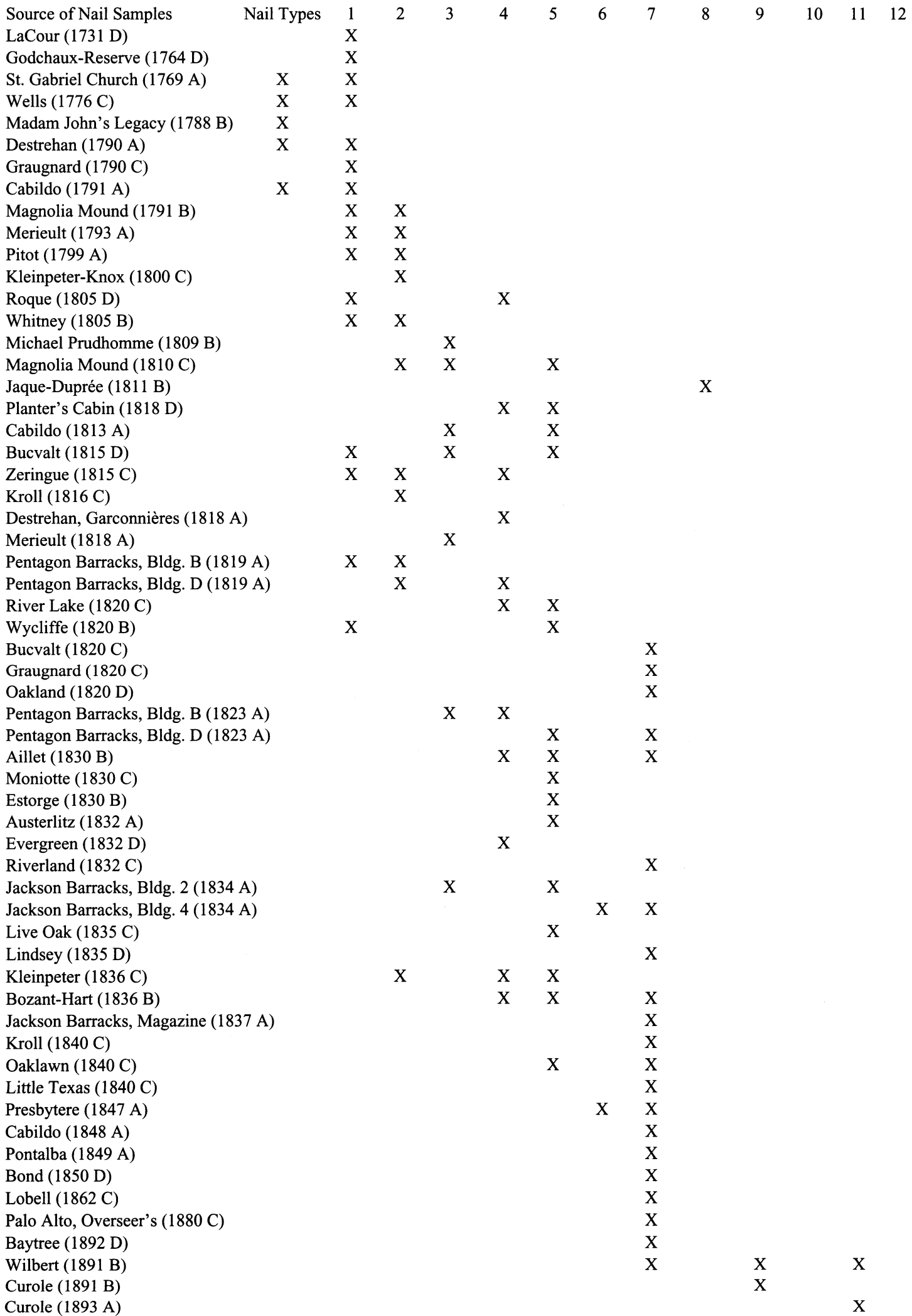


To determine if the nail is iron or steel the distinctive characteristics of iron are important; these include grain and possibly a poorly consolidated structure such as cold shuts and cracks described below. The absence of the typical characteristics of iron probably indicates steel. The transition from the use of iron to steel in the nail industry was not immediate, having begun in the mid-1880s and continued into the 1890 s.

Though not itself a dating factor, the general uniformity of the head and shaft, especially in a collection of similar nails from a site, usually indicates improved production methods, and therefore a later date. Heads located eccentrically on the shaft, misshapen heads, and shafts that have several tapers or diameters indicate early nails. The judgment of uniformity can be rather subjective, thus it is desirable to obtain a large nail sample.
The shape of the shaft, its cross section, and taper can be used to distinguish among wire, cut, and hand-made nails. Cut nails have parallel faces but cut faces that taper straight towards the point. Wire nails have parallel sides extending from the head to the point. Hand-made nails, naturally, exhibit the greatest variation in all aspects of shaft form. Generally, hand-made nails tend to taper on all sides to the point and maintain a square cross section, though many such nails have a rectangular cross section, with parallel sides, on the upper one-third to one-half before they gradually taper to the point. Handmade nails often exhibit hammer marks on the shaft and head, or other evidence of hand work.

Except for sprigs and brads all cut nails are grasped by a clamp at the upper end of the shaft for heading. The clamp leaves a deformation, referred to as the "pinch," under the head. De-

TABLE 2

FEATURES OF LOUISIANA NAIL TYPES

\begin{tabular}{|c|c|c|c|c|c|c|c|c|c|c|c|c|}
\hline \multicolumn{13}{|l|}{$\begin{array}{l}\text { Feature: Nail Type: } \\
\text { Shaft Section: }\end{array}$} \\
\hline square/rect & $\mathrm{X}$ & $\mathrm{x}$ & $\mathrm{X}$ & $\mathrm{X}$ & $\mathrm{X}$ & $\mathrm{X}$ & $\mathrm{X}$ & $\mathrm{X}$ & $\mathrm{x}$ & & & \\
\hline square & $\mathrm{X}$ & $\mathrm{X}$ & & & & & & & & & & \\
\hline Round & & & & & & & & & & & $\mathrm{X}$ & $\mathrm{X}$ \\
\hline \multicolumn{13}{|l|}{ Material: } \\
\hline Iron & $\mathrm{X}$ & $\mathrm{X}$ & $\mathrm{X}$ & $\mathrm{X}$ & $\mathrm{x}$ & $\mathrm{X}$ & $\mathrm{X}$ & $\mathrm{X}$ & $\mathrm{X}$ & & $\mathrm{X}$ & \\
\hline Steel & & & & & & & & & & $\mathrm{X}$ & & $\mathrm{X}$ \\
\hline \multicolumn{13}{|l|}{ Grain (iron only) } \\
\hline Cross & $\mathrm{X}$ & $\mathrm{X}$ & $\mathrm{X}$ & $\mathrm{X}$ & $\mathrm{X}$ & $\mathrm{X}$ & & & $\mathrm{X}$ & & & \\
\hline In-Line & & & & & & & $\mathrm{X}$ & $\mathrm{X}$ & & & $\mathrm{X}$ & \\
\hline $\begin{array}{l}\text { Rounded Points } \\
\text { (cut face view) }\end{array}$ & & & $\mathrm{X}$ & $\mathrm{X}$ & $\mathrm{X}$ & & & & & & & \\
\hline \multicolumn{13}{|l|}{ Shaft Shape: } \\
\hline Four Sides Taper & $\mathrm{X}$ & $\mathrm{X}$ & & & & & & & & & & \\
\hline Two Sides Taper & & $\mathrm{X}$ & $\mathrm{X}$ & $\mathrm{X}$ & $\mathrm{X}$ & $\mathrm{X}$ & $\mathrm{X}$ & $\mathrm{X}$ & $\mathrm{X}$ & $\mathrm{X}$ & & \\
\hline No Taper & & & & & & & & & & & $\mathrm{X}$ & $\mathrm{X}$ \\
\hline \multicolumn{13}{|l|}{ Burr } \\
\hline Same Face & & $\mathrm{X}$ & & & $\mathrm{X}$ & $\mathrm{X}$ & $\mathrm{X}$ & $\mathrm{X}$ & & $\mathrm{X}$ & & \\
\hline Opposite Faces & & & $\mathrm{X}$ & $\mathrm{X}$ & & & & & $\mathrm{X}$ & & & \\
\hline \multicolumn{13}{|l|}{ Header Clamp Pinch } \\
\hline Side-Pinched & & & $\mathrm{X}$ & $\mathrm{X}$ & $\mathrm{X}$ & & $\mathrm{X}$ & & & & & \\
\hline Face-Pinched & & & & & & $\mathrm{X}$ & & $\mathrm{X}$ & $\mathrm{X}$ & $\mathrm{X}$ & & \\
\hline Hand-Headed & $\mathrm{X}$ & $\mathrm{X}$ & $\mathrm{X}$ & & & & & & & & & \\
\hline Used: Beginning & 1699 & 1699 & 1791 & 1809 & 1805 & 1810 & 1834 & 1820 & 1811 & 1891 & 1875 & 1891 \\
\hline Ending & 1805 & 1820 & 1836 & 1834 & 1836 & 1840 & 1847 & 1891 & 1812 & 1893 & $1880 \mathrm{~s}$ & present \\
\hline
\end{tabular}



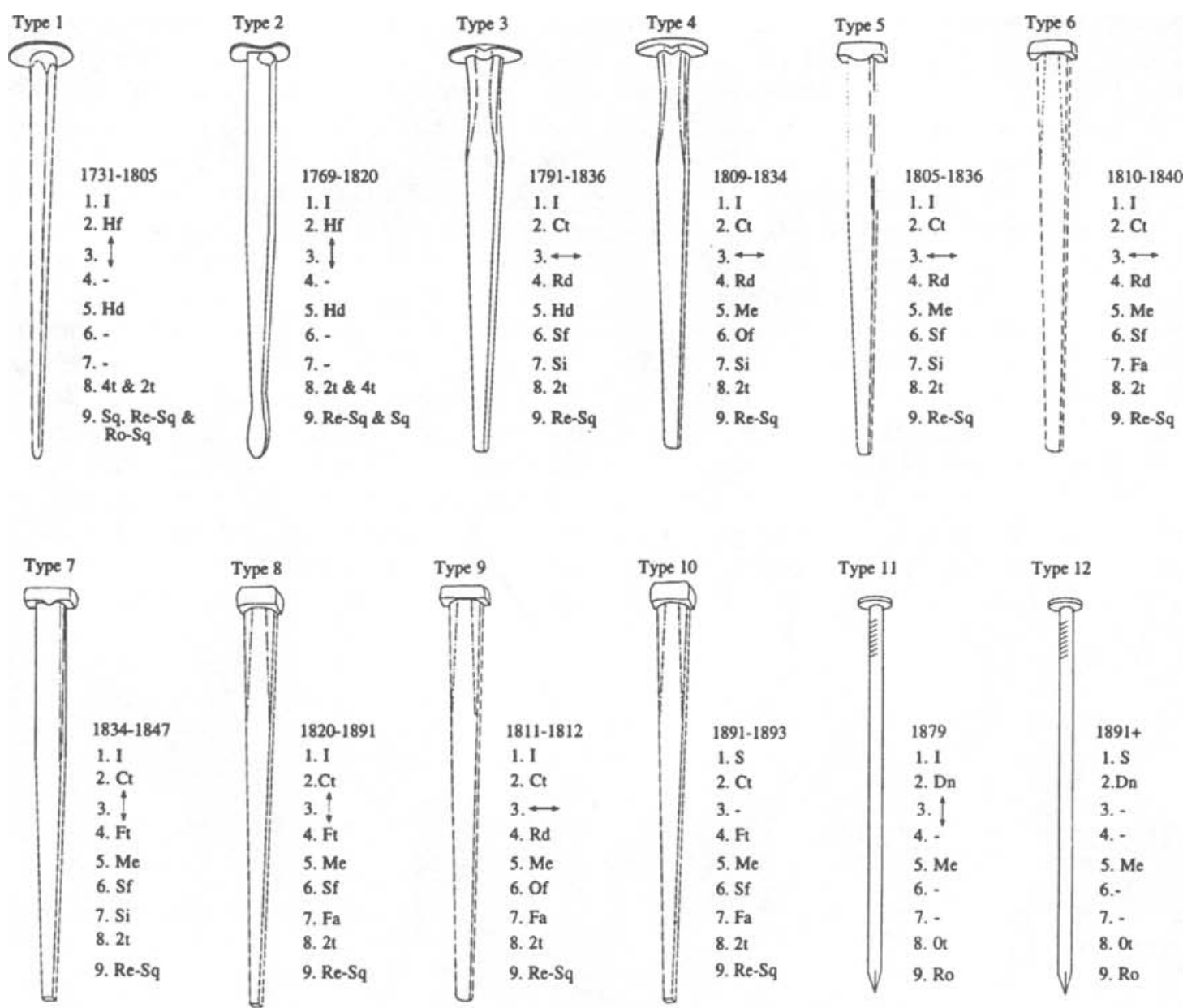

\section{Diagnostic Nail Features}

\begin{tabular}{|c|c|c|}
\hline Feature & Symbol & Meaning \\
\hline $\begin{array}{l}\text { 1. Metal: } \\
\text { 2. Mfg. Method }\end{array}$ & $\begin{array}{l}\text { I. S } \\
\text { Hf, Ct, Dn }\end{array}$ & $\begin{array}{l}\text { Iron, Steel } \\
\text { Hand-forged, Cut, Drawn }\end{array}$ \\
\hline 3. Grain (iron only) & $\dagger \leftrightarrow$ & In Line, Cross \\
\hline 4. Point (cut only) & $\mathrm{Rd}, \mathrm{Ft}$ & Round, Flat \\
\hline $\begin{array}{l}\text { 5. Head Mfg. } \\
\text { 6. Burr (cut only) }\end{array}$ & $\begin{array}{l}\text { Hd, Me } \\
\text { Sf, Of }\end{array}$ & $\begin{array}{l}\text { Hand, Machine } \\
\text { Same faces, Opposite faces }\end{array}$ \\
\hline 7. Pinch (cut only) & $\mathrm{Si}, \mathrm{Fa}$ & Side, Face \\
\hline 8. Shaft Taper & $4 t, 2 t, 0 t$ & Taper on: 4 sides, 2 sides, no taper \\
\hline 9. Shaft Section & Sq, Re, Ro & Square, Rectangular, Round \\
\hline
\end{tabular}

FIGURE 8. Louisiana Nail Types 
pending on the length of nail, the pinch usually extends down the shaft, generally for about oneeighth to one-quarter of its length. The pinch is relatively shorter on large nails and longer on small nails. Only cut nails are pinched, thus this feature is useful for establishing the type of nail. The earliest cut nails in Louisiana are pinched on their cut faces (side-pinched). Nails pinched on their faces (face-pinched) began to appear in Louisiana in the $1820 \mathrm{~s}$, though there is one face pinched type that was used on a house in 1811 . The pinch, however, is not chronologically significant by itself: similar nails were made throughout the 19th century, and are still manufactured, though now they are made of steel.

Variation in the point of wire nails does not appear to be temporally significant, though the point can be of great significance on cut nails. Generally, cut nails have a blunt point: the cut faces form an acute triangle that extends from the head and ends abruptly before meeting. Where the faces end, the flat point, is the edge of the nail plate. The point can indicate whether the nail was made from the early style nail plate or the later nail plates cut from sheets. The points of nails cut from narrow nail plates are slightly rounded from the front face to the back face. Nails made from nail plates that were cut from sheets have four sharp corners at the point. This feature can be used to help distinguish between cross-grained nails and grain-in-line nails, a difference that can be temporally significant. Among hand-made nails there is great variation in point styles. Some hand-made nails have burrs and a rectangular cross section, and can easily be mistaken for early hand-headed cut nails. It is here that the point type can be of use to the archaeologist. The points of cut nails are almost always blunt, while those of handmade nails are generally either sharply pointed or chisel-shaped. In addition, the point is formed by opposite faces tapering until they meet. Except for distinguishing between cut nails and hand-made nails, these variations do not appear to have any temporal value, though they probably had functional significance.
The burr can cause some unnecessary confusion. Burrs are found on the shafts of cut nails and may be present on some hand-made nails made from slit nail rods. The burr on cut nails indicates whether the cutting of the nail blank from the nail plate was done from the same side or opposite sides. Most of the early nail machines cut the nail blank from the same side of the nail plate, leaving the burr on opposite edges of the nail shaft. Most of the later machines cut the nail from opposite sides of the nail plate, leaving the burrs on the same face of the shaft. Burrs on the same face may indicate a more developed technology: either the nail plate was turned over after each cut or, more likely, the nail plate was fed into a nail machine having a reciprocating cutter with two cutting surfaces. The burr on hand-made nails made from slit stock is often obliterated during the forging of the nail, especially where the shaft is tapered to form the point. Sometimes it may be discerned along the edge as a cold shut, as noted below.

Cracks and cold shuts are characteristic of wrought iron. Cracks result from the fibers of unconsolidated iron opening as the metal is worked. The cracks occur along the grain, where the slag prevented a perfect union of the metal. On cross-grained nails the crack will run across the face, while on grain-in-line nails the cracks will run length-wise on the face. On the cut face of both kinds of nails there may be a crack, or even separation, running length-wise down the shaft. The heads of either kind can be cracked across the top in the direction of the cut faces. Cold shuts are unconsolidated metal folded against the body of the stock. There are numerous causes of cold shuts, but for the purposes of defining nails, they occur on handforged nails when the burr is hammered flat against the nail shaft.

All hand-made nails and early cut nails were hand-headed. Hand-formed nail heads are found in a plethora of styles. Though these styles may have a functional significance, they are not useful for establishing temporal significance. For instance, on cut nails, hand-heading indicates an 
early date of manufacture. Hand-formed nail heads tend not to be uniform and, on cut nails, are usually thinner than machine-formed heads. There will also be evidence of hammering on the head. Caution is advised, however, because the presence of shallow hammer marks on the heads of cut nails may be caused by the carpenter driving the nail rather than the nailer forming the head.

\section{Louisiana Nail Types}

Nails are assigned to one of the various types based on their possession of the requisite diagnostic features. The number assigned to any particular type has no significance, though it will be noticed that the first eight numbered types are also in chronological order; this is a reflection only of the evolution in the development of this system. Newly identified types can be added to this list by assigning the next vacant number. The dates of use given should be understood as a general period that a type was used because the dates are based on a limited survey of standing structures. The following list differs from that of Edwards and Wells (1993) by dropping their Type 9 nail. Edwards and the author think that the original Type 9 nail should probably be considered a variant of Type 7 nails. In its place a recently collected nail has been given the designation of Type 9, which is discussed under that heading below.

In the following section descriptions of some of the nail types include elements of the superficial appearance of the nail type. These superficial elements are included to aid the researcher in identifying the nail type to augment, and not to limit, the type description. In the cases in which the type description includes elements about the appearance it must be remembered that superficial elements are merely characteristic of many of the samples observed. In addition, there are some features that may have chronological significance, though these are not representative of technological developments. One of these is the length of pinch on side-pinched nails; the early nails tend to have a rather short pinched area compared to later nails. The intent is to illustrate a method of establishing a chronologically significant nail typology based on manufacturing and structural features, rather than on the appearance of a nail. Some examples of Louisiana nail types are illustrated in Figure 8.

Type 1. These are hand-made nails made from forged or drawn nail rods. Included in this type are Type 2 nails that do not exhibit burrs and other evidence characteristic of that type. A Type 1 nail is forged from an iron nail rod and exhibits hammer marks on both the shaft and head. The shaft is usually square and tapers evenly on all sides to the point. Heads are generally rather thin and may occasionally bend or even break loose from the shaft if pulled forcefully from the timber. The numerous head and point varieties have no temporal significance other than indicating that the nail is hand made.

Type 2. These nails are similar to the Type 1 except that they are made from slit nail rods and have burrs. Nails of this type are often rectangular from under the head to where the point taper begins. Cold shuts may be present on the shaft. Type 1 and Type 2 nails are found in many varieties, but no temporal value can be attached to the varieties. The technology that produced these nails pre-date the European settlement of Louisiana, so an early date for this type begins with the establishment of the French colony in 1699 at Mobile. Though hand-made nails may have been manufactured well into the 19th century, the latest date of use in Louisiana is 1820 .

Type 3. These nails are machine cut and handheaded. Because they were made from narrow rolled nail plates they are cross-grained and have points that are slightly rounded from the front face to the back face. The shaft is usually strongly side-pinched and the heads are thin. Depending on the size of the nail, the pinch extends only about one-fifth or one-sixth of the way down the length of the shaft from below the head. Burrs are on opposite faces of the shaft. 
Within a sample of nails of the same length and thickness from the same building there can be considerable variation in the width of the shaft and its degree of taper. This unevenness is an indication that the nail plate was fed into the shear by hand. The heads are generally a flat disk. Also a common sub-type of Type 3 was manufactured by hammering the heads from two angles, producing a narrow head that overhangs the cut faces, leaving a roof-like peak centered on the shaft. Type 3 use in Louisiana extends from 1791 to 1836 .

Type 4. Nails of this type are entirely machinemade cut nails. They are cross-grained and have points that are slightly rounded from front face to back face. Type 4 nails are side-pinched and usually have a flat, discoid head. Some samples of this type are distinguishable from Type 3 nails only by their thicker heads and general uniformity. Burrs are on opposite faces. In Louisiana these nails appear to have been used from 1809 to 1834 .

Type 5. These are entirely machine cut nails. They are cross-grained and have points that are slightly rounded from the front face to back face. They are uniformly cut and headed. The heads are roughly square, small, and thick. These are side-pinched nails. The pinch is rather long and shallow, making the upper one-third of the nail appear parallel when viewed from the face. The faces, when viewed from the cut face, bulge slightly. Though not common, these nails saw a rather long use in Louisiana from 1807 to 1836.

Type 6. Nails of this type are cross-grained cut nails and, like the other cross-grained nails, have points that are slightly rounded from the front face to back face. Type 6 nails are face-pinched and, depending on the size, the area deformed by the header extends one-fifth to one-tenth of the length of the nail. Burrs are on the same face. The outline and superficial appearance of these nails is often indistinguishable from that of later Type 7 iron nails and Type 10 steel nails, demonstrating the need for careful attention to the temporally significant features. These nails were used in building construction from 1810 to 1840 in Louisiana.

Type 7. These are side-pinched cut nails; however, the grain runs the length of the shaft, and all four corners of the point are flat. This indicates that the nail blanks were cut from nail plates that were sheared from wide, rolled sheets. Nails in a typical sample of Type 7 nails are uniform, have heads of moderate size, and have a long pinch extending nearly one-half down the shaft. A cross section through the shaft at the pinch describes a square with rounded corners. In Louisiana these nails saw use from 1834 to 1848 .

Type 8. These nails are grain-in-line, facepinched cut nails. Early nails of this type are more often found with cracks or even grain separation on the cut face than later nails. Their form is similar to that of Type 6 nails as well as Type 9 nails. Nails of this type are perfectly uniform and consistent within a sample. There are several styles of head, varying from small and rectangular to large and oval. This is the most common 19th century-nail, seeing long use in Louisiana from 1820 to 1891 .

Type 9. This is a cross-grained and face-pinched nail. It exhibits the point rounding common to cross-grained nails. The burrs are on opposite faces, otherwise it is indistinguishable from Type 6 nails. Its head is small, rectangular, and rather thin. This nail type has been found in only one house in Louisiana, dated 1811 or 1812 . This is a recently collected type of nail and replaces the former Type 9 nail of Edwards and Wells (1993).

Type 10. These are cut nails made of steel. In general outline this type resembles the earlier face-pinched cut nails (Types 6, 8, and 9). It is distinguishable from the Type 8 only in that it is made of steel rather than iron. The earliest appearance of Type 10 nails in Louisiana is 1891 . Steel cut nails are currently available at many hardware stores. 
Type 11. These are iron wire nails. The form is indistinguishable from modern steel wire nails. This type is poorly represented in Louisiana, and the provenience of the sample is highly questionable; so far only one house has provided nails of this type, and they were drawn from a roof lath in an 18th century house. Interestingly, this lath also had Type 1, Type 2, and Type 8 nails. The building is believed to have been re-roofed in the late $1870 \mathrm{~s}$ as a part of a general rebuild of the structure.

Type 12. These are modern steel wire nails. The earliest example found in Louisiana is from 1891.

\section{Conclusion}

The establishment of a useful and accurate nail chronology requires a nail typology that is based on readily observable, objective criteria. Each of the evolving methods of nail manufacture leaves readily identifiable features that are indicative of the technology used in the manufacture of nails. The manufacturing technology changed over the course of time, therefore these features are temporally significant. A typology based on these features provides the best basis for the establishment of a nail chronology.

The Louisiana Nail Chronology was developed from samples of nails drawn from houses in southern Louisiana and Natchitoches Parish, Louisiana. The survey provided dates of actual use for the types of nails collected. These data supplemented information derived from historical research into the development of nail manufacturing technology. Investigation further afield indicates that the chronology may have a general applicability to the greater Mississippi and Ohio Valleys. That the Louisiana Nail Chronology can be applied to those areas may be hypothesized, based on the existence of the extensive river-born and coastal trade that linked Louisiana with nail manufacturing centers in Pittsburgh, Wheeling, and elsewhere. The development of similar, locally adjusted, nail chronologies on the
East Coast and the Mississippi Valley using the methods outlined here can test this hypothesis.

\section{Nail Terms}

*denotes terms developed by the author and Jay Edwards

Alloy: A molecular combination of two or more metals: iron + carbon $=$ steel. Wrought iron is a mixture, not an alloy.

Brad: A forged or cut nail that is "7" shaped. Cut brads do not go through an additional heading step because the head is sheared with the shaft. This type of nail has been made from antiquity, but may be dated on technological features. One of the few traditionally named types included here because it is clearly defined.

Burr: Burrs may be found on cut nails and nails made from slitted rods. The cutting tool leaves a sharp, rough flange of metal on the lower side of the shaft as it cuts through the metal stock. The edge above the burr may be slightly beveled or rounded. Burrs may also be found on handmade nails. Such burrs are found on nails made from slit nail rods. In some cases, burrs can be left on hand-made nails if they were seated in a poorly fitted header.

Clinch: To bend and hammer the nail's exposed point end flat against the wood; done to prevent its loosening.

Cold shut: An unconsolidated fold caused by hammering the burr against the shaft at a too low heat to weld it to the body of the nail.

Cross-grained nails: Cut nails sheared from the end of a narrow nail plate that has the grain running length-wise. The earliest cut nails are cross grained. See "grain."

Cut face*: The two opposite surfaces of a cut nail that show the dragging of the shear. The upper edge may be slightly rounded where the 
shear entered the nail plate; lower edge will have the burr. See "face."

Cut nail: A machine-made nail. Cut nails are made by cutting the blank off the end of a long strip of iron or steel. The blank is wider at one end than the other. The wide end is mechanically held and is then headed by hand or by machine. The point is left flat.

Drag marks: Striations below the head of handmade nails caused when being seated in the header. Drag marks are also seen on the cut face of cut nails. These are caused by the shear as it slices through the metal, pulling the metal in the direction of the burr. The burr is also the result of dragging.

Drawn, Draw-out: Blacksmith term for lengthening and narrowing the metal. A point is drawn on a nail shaft by hammering the rod on two sides $90^{\circ}$ apart. The opposite of "upset."

Face*: The surface of the shaft that is $90^{\circ}$ from the cut face, and is the wider of the two pairs of faces. No distinction is made between front and back faces. See "cut face."

Forged nail: A hand-made nail. The shaft is formed from an iron rod using a hand hammer and an anvil. One end is pointed and then inserted into a header. The head is formed by hammering down on the end of the shaft that projects out of the header.

Grain: Striations in the metal that are characteristic of wrought iron. Iron is strongest when the load is applied across the grain because the slag that forms the grain prevents the metal from having a uniform bond over its whole surface. This is why grain-in-line nails can be clinched reliably and cross grained nails cannot. Steel has no grain because it has a crystalline structure.

Head: That part of a nail that is driven by the carpenter's hammer. Sprigs have no apparent head. Hand-formed heads are usually faceted by the numerous blows made during the heading process. Machine-headed nails will have a flat, smooth surface except for some modern cut nails that have a hemispherical knob centered on the head.

Header: 1. A tool used to form the head of hand forged nails. The most common form of header is a flat bar pierced with a hole the size of the nail shaft. The shaft is inserted into the hole and the header is rested over a hole (the pritchel hole) in the anvil, with the shaft point down. A part of the shaft projects above the header and is hammered down to form the head. 2. A machine or a part of a machine that grasps the shaft of a nail for heading.

Nail bar: A wrought iron strip from which nail rods were slit.

Nail plate: The stock from which cut nails are cut. These were originally produced in the early rolling mills with the grain running their length. Nails cut off these early nail plates are cross grained. Nail plates were later cut from sheet iron in such a way that the grain of the iron of nails cut from them ran the length of the nails. See "grain."

Nail rod: Square or rectangular rods from which some hand-made nails were made. Some nail rods were produced by rolling and slitting mills. Nails made from such rods may exhibit burrs on the same face, between the head and part of the shaft that is drawn out for the point.

Penny, penny weight: English system of nail sizing. It has several meanings: number of nails per pound, price in pence for a hundred nails, number of nails one could get for a "dinar" or penny (hence the abbreviation "d" as in 16d). Today it is standardized to describe the size of a wire nail. Because the term is vague it is not used here.

Pinch*: On cut nails: the area under the head that is grasped for heading. When the unheaded 
shaft of a cut nail is mechanically held for the heading operation, the part held is deformed on the shaft under the head. Earlier nails are generally deformed on the cut face and are described here as being "side-pinched." Later nails are deformed on the front and back and are described as being "face-pinched."

Point: The end opposite the head. Points may be sharp (all four sides meet), blunt (sides stop abruptly before meeting, forming a square or rectangle when viewed from above), or chisel (two opposite faces meet).

Rolling and slitting: Two stages in the process of making nail rods. The early rollers were about 8-10 in. wide and 10-12 in. thick. By the 1830 s rollers were $3 \mathrm{ft}$. or more wide and over $2 \mathrm{ft}$. in diameter. To make a flat nail bar the iron ingot was fed into the rollers at a high heat. Slitting follows rolling; it is the longitudinal cutting of the flat nail bar into several long nail rods.

Rose head: English term for a faceted discoid head on a hand-made nail. This term is not used here because it is too vague to be useful for describing the enormous variation in head styles.

Shaft: Body of a nail extending from under the head to the point.

Shear: A cutting tool, usually with one moving edge and a lower stationary edge. Shearing is cutting across the width.

Slit: To cut a bar down its length. A slitter is a machine tool used in the manufacturing of nail rods consisting of an upper and a lower set of interlocking, disk-shaped cutters. The slitter cuts the nail plate longitudinally into nail rods. Though nails made from these rods often exhibit cut faces, they may be distinguished from early machine-made nails by the slitted nail's hand forged heads and grain running the length of the shaft.
Spike: A large nail. Imprecise term standardized too recently to be useful for describing hand-made and cut nails.

Sprig: A headless nail. This term can be defined clearly enough to be useful for describing hand-made and cut nails.

Steel: An iron-carbon alloy, usually having less than $2 \%$ carbon. The steel used in nails usually has less than $0.1 \%$ carbon. Steel began to supplant wrought iron in nail manufacturing in the 1880s. All modern wire nails are steel. Etched steel shows a very fine crystalline structure.

Upset: Blacksmith term for making the iron shorter and thicker. The head of a hand-headed nail is formed by upsetting the end of the shaft.

Wire nail: Machine-made nails made from round wire. In the 19th century these were called "French Points" and "French nails," after the country in which they were developed.

Wrought iron: Iron/silica amalgam produced by working a lump (bloom) of iron using a silicious flux as a part of the manufacturing process. Wrought iron is soft and more resistant to corrosion than steel. When etched the metal reveals a wood-like grain structure.

\section{REFERENCES}

Agricola, Georgius

1950 De Re Metallica, translated and edited by Herbert Clark Hoover and Lou Henry Hoover. Reprint of 1912 edition, originally published in 1556. Dover, New York.

Aston, James, And Edward B. Story

1939 Wrought Iron. A. M. Beyers, Pittsburgh.

Binning, Arthur Cecil

1938 Pennsylvania Iron Manufacture In the Eighteenth Century. Pennsylvania Historical Commission, Harrisburg.

CAMPBell, HaRry L.

1940 The Working, Heat Treating, and Welding of Steel. John Wiley \& Sons, New York. 


\section{Clark, Donald (editor)}

1978 The Encyclopedia of How It's Made. A\& W Publishers, New York.

Committee of Rod and Drawn Wire Producers

1969 Designer's Handbook: Steel Wire. American Iron and Steel Institute, New York.

Daumas, Maurice

1964 A History of Technology and Invention, Vol. 2, translated by Eileen Hennessy. Crown Publishers, New York.

Dickinson, H. W.

1939 A Short History of the Steam Engine. Cambridge University Press, Cambridge.

DIDEROT, DENIS

1765 Recueilde Planches, surles Sciences, les Arts Libéraux, et les Arts Méchaniques, Aves Leur Explication. Paris.

Edwards, Jay D., and Tom Wells

1993 Historic Louisiana Nails: Aids to the Dating of Old Houses. Geo-Science Publications, Louisiana State University, Baton Rouge.

FERGuSON, EUGENE S. (EDITOR)

1965 Early Engineering Reminiscences (1815-1840) of George Escol Sellers. Smithsonian Institution, Bulletin 238. Washington.

HABAKKUK, H. J.

1962 American and British Technology in the Nineteenth Century: The Search for Labour-Saving Inventions. Cambridge University Press, Oxford.

Heitmann, John A.

1989 Peter Shoenberger. In Iron and Steel in the Nineteenth Century, edited by Paul Paskoff, pp. 309-311. Facts on File and Bruccoli Clark Layman, New York.

THE IRON AGE

1898 The Pioneer Wire Nail Manufacturer. The Iron Age $62(8)$.

KAUfFMAN, HenRY J.

1966 Early American Ironware. Charles E. Tuttle, Rutland, VT.

LOVEDAY, AMOs J., JR.

1983 The Riseand Decline of the American Cut Nail Industry: A Study in the Relationships of Technology, Business Organization, and Management Techniques. Greenwood, Westport, CT.
Mackintosh-Hemphill Company

1953 Rolling Mills, Rolls, and Roll Making. MackintoshHemphill, Pittsburgh.

Martineau, R. F.

1866 Birmingham and Midland Hardware District, edited by Samuel Timmins. Robert Hardwicke, London.

Mercer, Henry C.

1924 The Dating of Old Houses. A Paper Read by Dr. Henry C. Mercer, of Doylestown, $\mathrm{Pa}$. at a Meeting of the Bucks County Historical Society, at New Hope, Bucks County, Pa., October 13, 1923. Bucks County Historical Society Papers, 5.

Motт, R. A.

1983 Henry Cort: the Great Finer, edited by Peter Singer. The Metals Society, London.

Nelson, Lee H.

1968 Nail Chronology as an Aid to Dating Old Buildings. American Association for State and Local History, Technical Leaflet No. 48. Nashville.

NoËL HuME, IVoR

1972 A Guide to Artifacts of Colonial America. Alfred Knopf, New York.

Phillips, Maureen Kathleen

1989 A Revised Chronology of Cut Nails in New England 1790-1820: A Case Study of the Spencer-Pierce-Little House Addition. Unpublished Master's thesis, Boston University, Boston.

Rowland, Dunbar, AND A. G. SANDERS

1984 Mississippi Provincial Archives: French Dominion, 1749-1763, Vol. 5, revised and edited by Patricia Kay Galloway, Louisiana State University Press, Baton Rouge.

SCHOENHOF, JACOB

1974 The Economy of High Wages. Reprint of 1892 edition. Garland, New York.

URE, ANDREW

1865 A Dictionary of Arts, Manufactures, and Mines, Vol.2. D. Appleton, New York.

TOM WELLS 838 AMERICA Street BATON Rouge, LA 70802 